\title{
APPLICATION OF EXACT ELEMENT-METHOD ON CALCULATION OF FORM-FINDING AND UNSTRESSED LENGTH OF CABLE
}

\author{
Li Zhou $^{1}$,Wang Ronghui ${ }^{1,2}$,Wei Yuancheng ${ }^{3}$,Huang Xiaofeng ${ }^{1}$
}

${ }^{1}$ School of Civil Engineering and Transportation, South China university of technology(976112542@qq.com)

${ }^{2}$ State Key Laboratory of Subtropical Building Science

${ }^{3}$ JiangXi Electric Power Design Institute

\begin{abstract}
The problem of form-finding for the suspended cable is actually the problem of determining all key points' coordinates on main cable, which are by equilibrium relation on the horizontal force, main cable sagitta and lifting point force under the precondition of determining the endpoint's boundary conditions of cable segment. According from the static equilibrium relationship of cable element, based on the analysis of its analytical solution process, in this paper, the cable elements are divided into two types in accordance withthe vertical distribution load along the arc length and along the string length, the corresponding shape curve of cable element is the parabola and the catenary, and with parabolic results as its initial value for the iteration of nonlinear solution, then cable element eventually converge for the catenary. And based on the exact coordinates results, the calculation method of the length without stress is presented, and compiled corresponding computational procedures. By comparing the results of form-finding and the cable-length in non-stress according to program compiled and the results from the finite element software and the measured value of Aizhai suspension bridge, compared with the nonlinear finite element method, it confirmed the method requireing smaller dividing element density, the convergence speed is quicker and the results can ensure the precision.
\end{abstract}

Keywords: Form-finding; Exact coordinates ; Iteration; Suspension cable.

\section{INTRODUCTION}

Finding Cable form is to determine the initial equilibrium state of cable, the core issue in static analysis on suspension bridge. Based on the different times, the static analysis methods can be classified into three categories: Elastic Theory Method, Deflection Method and Nonlinear Finite Element Method ${ }^{[1-3]}$ which is widely applied interiorly, while more calculation methods have presented abroad such as Force Density Method ${ }^{[4]}$ and Dynamic Relaxation Method ${ }^{[5]}$. In those methods cable segments are usually taken consider into approximate shape, for example, to regard 
the main cable form under horizontal of loads as second-degree parabola in elastic theory method, parabola in deflection method and bar elements ${ }^{[6]}$ in unit density enough cases in nonlinear finite element method. However, the cable actually has a sag.

The paper mainly introduces a method on the basis of the nonlinear finite element method, in which the accurately endpoint coordinates of cable unit could be determined by iteration with the initial parabolic value into the accurate curve of the catenary, in other words, to obtain ultimately precise cable form under dead loads. The method sets out from ordinary differential equations of equilibrium for cable unit, establishes the equations of the relationship between cable unit terminal points' perpendicular coordinates and loads on it, and gets the precise coordinates through solving the equations. Eventually, the form of the whole cable segment under constant loads can be obtained by means of integrating cable units into whole cable segment. Compared to the Nonlinear Finite Element Method, this method can reduce divided unit density so as to improve the operation speed and will not affect the accuracy of the results, for it Just need divide unit on the lifting point.

\section{GENERAL SITUATION OF ENGINEERING EXAMPLE}

This article takes Aizhai suspension bridge as a engineering case for Analysing. The main cables' span arrangement of Aizhai suspension bridge is $242 m+1176 m+116 m$, the full length of main beam is $1000.5 m$, the cross direction of main bridge has set $2 \%$ cross slope, the net width of bridge floor system is $24 \mathrm{~m}$, the full width steel truss stiffening girder is $27 \mathrm{~m}$. This bridge use two main cables with plane arrangement, the rise-span ratio of main cable is $\mathrm{F} / \mathrm{L}=1 / 9.6$, the center distance is $27 \mathrm{~m}$. The bridge use 68 pairs of slings, and the standard spacing of slings is $14.5 \mathrm{~m}$. Furthermore, a pair of sling has been anchored in rock away from the first pair of sling $29 \mathrm{~m}$ in the JISHOU side, and two pairs of slings with $29 \mathrm{~m}$ spacing have been anchored in rock away from the first pair of sling 29m in CHADONG side. The height of girder in main span (main truss center line) is $7.5 \mathrm{~m}$. Vertical bearing and resisted wind bearing have been set on the abutment, and elastic inclined cable-stayed buckles have been set on the mid-span. The cable tower of JISHOU side used double column type gate-shaped frame, which including spread foundation, tower base, tower column (upper tower column, middle tower column, lower tower column) and beam (upper beam, middle cross beam). The height of the tower is $134.016 \mathrm{~m}$ (including $4 \mathrm{~m}$ as to the height of the hood) from pile cap above. The cross direction of the tower is outward incline from up and down, and two beams (upper beam, middle cross beam) have been set on the tower. The cable tower of CHADONG side also used double column type gate-shaped frame, which including spread foundation, tower base, tower column (upper tower column, lower tower column) and beam. The height of the tower is $61.924 \mathrm{~m}$ (including $3.6 \mathrm{~m}$ as to the height of the hood) from pile cap above. The cross direction of the tower is vertical, it has set upper beam and tower base which located on the separated spread foundation. The main girder is using steel truss 
stiffening girder of $1000.5 \mathrm{~m}$ long, which is comprised of main truss, top bracing, lower bracing and transverse truss. The bridge floor system adopted the steel-concrete composite structure which is the combination of vertical flanged beam and concrete slab. The rise-span ratio of main cable is $1 / 9.6$, the main cables' computational span of main span is $1176 \mathrm{~m}$, the main cables' computational span of side span in JISHOU side is $242 \mathrm{~m}$, the main cables' computational span of side span in CHADONG side is $116 \mathrm{~m}$. The general arrangement of this bridge has shown in Figure 1.

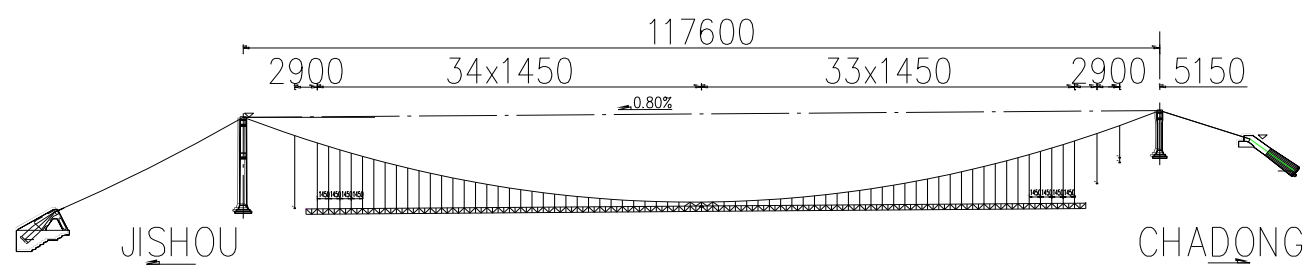

Figure 1. The overall layout of AiZhai suspension bridge

\section{THEORETICAL ELABORATION OF SHAPE FINDING}

As figure 2 shows, it's a chart of equilibrium relation of cable element. For plane problem, are the lateral and vertical distributed load along the $x$ direction of cable element, $T, d T$ are axial tension of cable element, $H, d H, Q, d Q$ are the $x$ and $z$ direction component of axial tension.

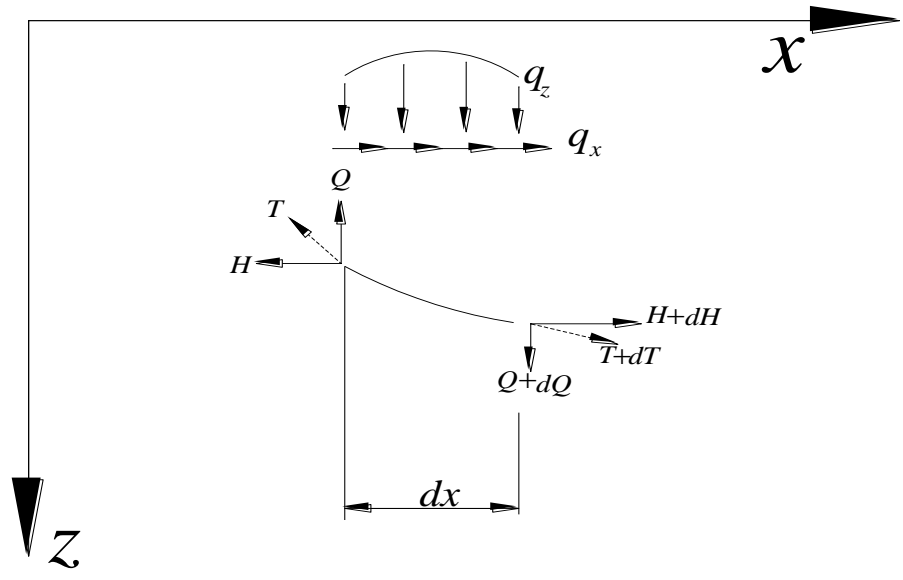

Fig.2 Cable element equilibrium diagram

According to the equilibrium relation of horizontal and vertical ${ }^{[7]}$, we have:

$$
\begin{gathered}
H=q_{x} \cdot d x+H+d H \\
Q=q_{z} \cdot d x+Q+d Q
\end{gathered}
$$

Hence:

$$
d H / d x+q_{x}=0
$$




$$
d Q / d x+q_{z}=0
$$

Where $Q=H \cdot d z / d x$, Therefore, equation (b) can be change as follows:

$$
\left(H z^{\prime}\right)^{\prime}+q_{z}=0
$$

In this paper only the condition of in-plane and $q_{x}=0$ is considered. According to equation (a), we can know that $H$ is a constant which has nothing to do with independent variable $x$. The equation (2b) is a differential equation about $x$, when $q_{z}$ is assumed to be the uniform load $q_{0}$ which distribute along the chord length of cable, and $q_{0}=d g / d l$, there $d g$ is the deadweight of cable element, then the shape of cable element will be parabola in this case. And when $q$ is assumed to be the uniform load which distribute along the cable, there $q_{z}=q_{0} \cdot \sqrt{1+\left(z^{\prime}\right)^{2}}$, in this case the shape of cable element will be catenary which approach the real shape. Finding the solution of $z(x)$ in equation (2b) is so called shape finding.

\subsection{To find the horizontal force $H$}

As shown in Figure 2, the cable unit is under the action of the uniformly distributed Load along the cable arc length $q_{z}$, the curve equation(3) for the initial state of the cable element can be solved from formula $(2 b)$.

$$
z=\frac{H}{q}\left[\operatorname{ch} \alpha-\operatorname{ch}\left(\frac{q_{0}\left(x-x_{1}\right)}{l}-\alpha\right)\right]+z_{1}
$$

Hypothesizing that the left end point is the origin point in the local coordinate system ,then ,formula(3)can be changed into formula(3a):

$$
z=\frac{H}{q}\left[\operatorname{ch} \alpha-\operatorname{ch}\left(\frac{2 \beta x}{l}-\alpha\right)\right]
$$

In the formula(3a),

$$
\begin{aligned}
& \alpha=\operatorname{Arcsh}\left(\frac{\beta h / l}{\operatorname{sh} \beta}\right)+\beta, \\
& \beta=\frac{q_{0} l}{2 H} ;
\end{aligned}
$$

Then the relationship between the cable sag and the horizontal cable force can be described as formula( $3 c)$, which is derived by the equation( $3 a)$.

$$
f=\frac{H}{q}[\operatorname{ch} \alpha-\operatorname{ch}(\beta-\alpha)]-\frac{h}{2}
$$

The cable sag for initial state of cable can be determined by design, then the horizontal cable force can be determined by equation ( $3 \mathrm{c}$ ). Therefore, the force $\mathrm{H}$ is supposed as a known condition in the following. 


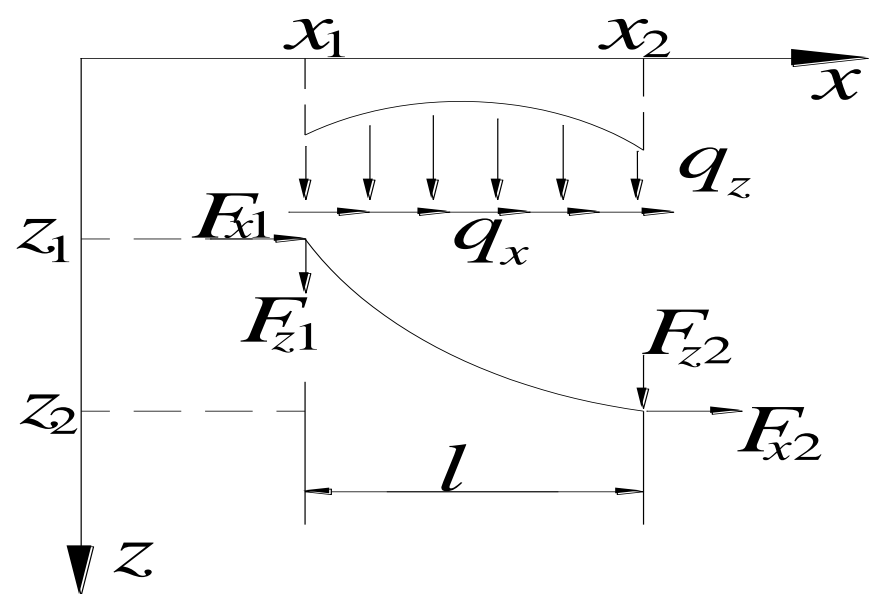

Fig.3 The diagram of cable element under force

As shown in Figure 3,it's an cable element under force in a local coordinate system, in which $F_{x i}$ is the horizontal force and $F_{z i}$ is the vertical force for the cable element nodes, $z_{i}$ is the vertical coordinates for the cable element nodes, they can also be written in vector form as below:

$$
F_{z}^{e}=\left[\begin{array}{l}
F_{z 1} \\
F_{z 2}
\end{array}\right], \quad z^{e}=\left[\begin{array}{l}
z_{1} \\
z_{2}
\end{array}\right]
$$

It is easy to know the relationship of the nodal force and the vertical coordinates for every node:

$$
F_{z i}=F_{x i} \cdot z^{\prime}\left(x_{i}\right)
$$

\subsection{As shown in figure 2,it's a cable element under vertical distributed load}

along the chord length of the cable element, , Namely $q_{x}=0, q_{z}=q_{0}$ when,cable element's shape is parabola.

By the equation (2b),it is easy to get cable element analytical solution of the form as below:

$$
z(x)=N_{1}(x) \cdot z_{1}+N_{2}(x) \cdot z_{2}+D(x)
$$

In formula(5), $N_{1}(x), N_{2}(x)$ is a shape function , $D(x)$ is a particular solution of the original differential equation; at the time,the relationship of $z(x)$ and the vertical coordinates $z_{1}, z_{2}$ of the endpoint are linear.Formula(6) is available from equation(5) and (4):

$$
\left[\begin{array}{l}
F_{z 1} \\
F_{z 2}
\end{array}\right]=\left[\begin{array}{ll}
F_{x 1} N_{1}^{\prime}\left(x_{1}\right) & F_{x 1} N_{2}^{\prime}\left(x_{1}\right) \\
F_{x 1} N_{1}^{\prime}\left(x_{2}\right) & F_{x 1} N_{2}^{\prime}\left(x_{2}\right)
\end{array}\right] \cdot\left[\begin{array}{l}
z_{1} \\
z_{2}
\end{array}\right]+\left[\begin{array}{l}
F_{x 1} D^{\prime}\left(x_{1}\right) \\
F_{x 2} D^{\prime}\left(x_{2}\right)
\end{array}\right]
$$

It is Easy to obtain the shape function as below: 


$$
N_{1}(x)=\frac{x_{2}-x}{l}, N_{2}(x)=\frac{x-x_{1}}{l}, D(x)=\frac{q_{0}\left(x-x_{1}\right)\left(x_{2}-x\right)}{2 H_{0}} ;
$$

Then formula (6) change into :

$$
\left[\begin{array}{l}
F_{z 1} \\
F_{z 2}
\end{array}\right]=\frac{H_{0}}{l}\left[\begin{array}{cc}
1 & -1 \\
-1 & 1
\end{array}\right] \cdot\left[\begin{array}{l}
z_{1} \\
z_{2}
\end{array}\right]+\frac{q_{0} l}{2}\left[\begin{array}{l}
1 \\
1
\end{array}\right]
$$

It is assumed $k^{e}=\frac{H_{0}}{l}\left[\begin{array}{cc}1 & -1 \\ -1 & 1\end{array}\right]$, which is called the element stiffness matrix, $P_{E}^{e}=-\frac{q_{0} l}{2}\left[\begin{array}{l}1 \\ 1\end{array}\right]$ is known as the element equivalent nodal loads matrix, then equation (6a) can change into the following type of element stiffness equation:

$$
F^{e}=F_{z}^{e}+P_{E}^{e}=k^{e} \cdot z^{e}
$$

Then the direct nodal force vector $F_{z}^{e}$,equivalent nodal force vector $P_{E}^{e}$, stiffness matrix $k^{e}$ of each cable element can be superposed into nodal force vector $F$ and stiffness matrix $K$ for the whole cable, as a result, we can have the global stiffness equation as the following form :

$$
F=K \cdot Z
$$

In Equation (7) $Z$ is the exact vertical coordinates vector of all node .

\subsection{As shown in figure 1,it's a cable element under vertical distributed load}

along the arc length of the cable element, , Namely $q_{x}=0, q_{z}=q_{0} \cdot \sqrt{1+\left(z^{\prime}\right)^{2}}$.when, cable element's shape is catenary.

Then Put $q_{z}$ into formula (2b) ,it is easy to obtain the analytical solution equation (3); In the equation(3),

$$
\begin{aligned}
& \alpha=\operatorname{Arcsh}\left(\frac{q_{0}}{2 H_{0}} \cdot \frac{z_{2}-z_{1}}{\operatorname{sh} \beta}\right)+\beta, \\
& \beta=\frac{q_{0} l}{2 H}
\end{aligned}
$$

It is shown the relationship of $z(x)$ and $z_{1}, z_{2}$ is non-linear in equation (3). Assumed the parabola as the initial shape for the cable element, we can obtain - the approximate coordinates of the initial vertical vector $z_{0}$ of the cable, then put $z_{0}^{e}$ of any element into equation (3), we can obtain the curve equation $z(x)$ of the corresponding element; then take $z(x)$ into equation (4), then $F_{z}^{e}$ will be spreaded by the Taylor formula at the approximate solution $z_{0}^{e}$, and omit the second order trace, 
we can get formula (8) as below:

$$
F_{z}^{e}\left(z^{e}\right) \approx F_{z}^{e}\left(z^{e}\right)+\frac{\partial F^{e}\left(z^{e}\right)}{\partial z^{e}} \cdot\left(z^{e}-z^{e}\right)
$$

Assumed $\stackrel{-}{k}^{e}=\frac{\partial F^{e}\left(z^{e}\right)}{\partial z^{e}}$, it is called the element stiffness matrix, and $\bar{p}_{E}^{e}=\bar{k}^{e} z^{e}-F_{z}^{e}\left(z^{e}\right)$ known as the element equivalent nodal load vector, then equation (8) can change into the following element stiffness equation:

$$
F^{e}=F_{z}^{e}\left(z^{e}\right)+\bar{p}_{E}^{e}=\bar{k}^{e} z^{e}
$$

It is easy to know:

$$
k^{e}=\frac{q_{0}}{2 \operatorname{sh} \beta \operatorname{csh}(\bar{\alpha}-\beta)}\left[\begin{array}{cc}
\operatorname{csh} \bar{\alpha} & -\operatorname{csh} \bar{\alpha} \\
-\operatorname{csh}(\alpha-2 \beta) & \operatorname{csh}(\bar{\alpha}-2 \beta)
\end{array}\right], \quad \overline{p_{E}^{e}}=k^{e} z^{e}-F_{z}^{e}\left(z^{e}\right)
$$

In formula(9a), $\bar{\alpha}$ and $\beta$ can be obtained by putting $\bar{z}^{e}$ into equation (3d).

Then the direct nodal force vector $F_{z}^{e}$,equivalent nodal force vector $\bar{p}_{E}^{e}$, stiffness matrix $F_{z}^{e}$ of each cable element can be superposed into nodal force vector $\bar{F}$ and stiffness matrix $\bar{K}$ for the whole cable, as a result, we can have the global stiffness equation as the following form :

$$
\bar{F}=\bar{K} \cdot Z
$$

In equation(10) $\bar{F}$ is the node force vector for the whole cable, $\bar{K}$ is the global stiffness matrix, $Z$ is the vertical coordinates vector of each node for the whole cable.

\section{CALCULATION METHOD FOR UNSTRESSED LENGTH OF THE CABLE}

In above text, every exact nodal coordinate $z_{0}$ can be known,then we can obtain every cable element'catenary equation $z=f(x)$. Also we can get axial force of every cable element as below:

$$
\mathrm{F}=\sqrt{\mathrm{F}_{\mathrm{xi}}^{2}+\mathrm{F}_{\mathrm{zi}}^{2}}
$$

Namely:

$$
\mathrm{F}=\mathrm{F}_{\mathrm{xi}} \sqrt{1+\left[\mathrm{z}^{\prime}(\mathrm{x})\right]^{2}}
$$

Assumed the extention length of cable element under the axial force is $\Delta l$, based on the relationship of stress and strain, we can get equation (12) as below: 


$$
\Delta l=\frac{F}{E A} d s
$$

In the above equation:

$$
\mathrm{ds}=\sqrt{1+\mathrm{z}^{2}} \cdot \mathrm{dx}
$$

Then we can get:

$$
\Delta l=\frac{F}{E A} \sqrt{1+z^{\prime 2}} d x
$$

As a result,the extention length of any cable element is known from the below equation:

$$
\Delta L i=\int_{x_{i}}^{x_{i+1}} \frac{F_{x_{i}}}{E A}\left(1+z^{\prime 2}\right) d x
$$

Then the extention length of the whole cable is:

$$
\Delta L=\sum_{i=1}^{n} \Delta L_{i}
$$

Every cable element length under uniform loads is:

$$
L L_{i}=\int_{x_{i}}^{x_{i+1}} 1 \cdot d s=\int_{x_{i}}^{x_{1+i}} \sqrt{1+z^{\prime 2}} d s
$$

So the length of the whole cable is:

$$
L L=\sum_{i=1}^{n} L L_{i}
$$

Finaly we can get the unstressed length of the whole cable as below:

$$
L_{0}=L L-\Delta L
$$

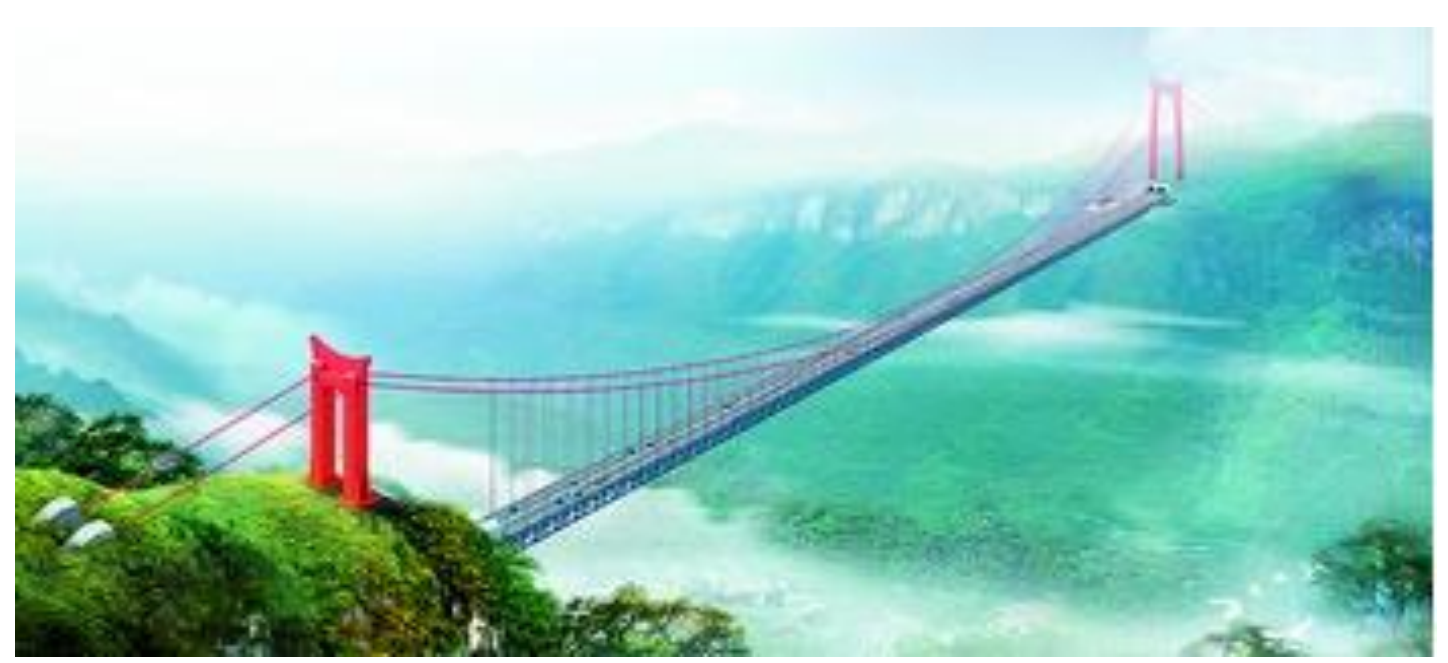

Fig.4 The designsketch of AiZhai suspension bridge 


\section{FLOW CHART OF CALCULATION PROCEDURE}

In the process of practical calculation, firstly take vertical uniform loads on element as $q_{z}=q_{0}$,on the case, the shape of cable element is parabolic, so we can get a group of nodal vertical coordinates as initial solution $\bar{z}$; then take $q_{z}=q_{0} \cdot \sqrt{1+\left(z^{\prime}\right)^{2}}$, and take $\bar{z}$ as a known initial value, so we can obtain a group of new nodal vertical coordinates, which will be the new initial value for the next calculation. Then, the liner of cable element will convergence from parabolic to catenary step by step. When the convergence solution can fufill the precision asked for, the calculation procedure can break, and we can get the exact vertical coordinates of all nodes.

And then take the exact nodal vertical coordinates as known conditions, we can get the curve equation of all cable elements. Finally we can obtain the original length and extension length and unstressed length on basis of equations(13),(14),(13a),(14a).detailed calculation flow chart as shown in figure 5.

Take $q_{z}=q_{0}$ into equation $\left(H z^{\prime}\right)^{\prime}+q_{z}=0$, get parabolic analytical solution $z(x)$

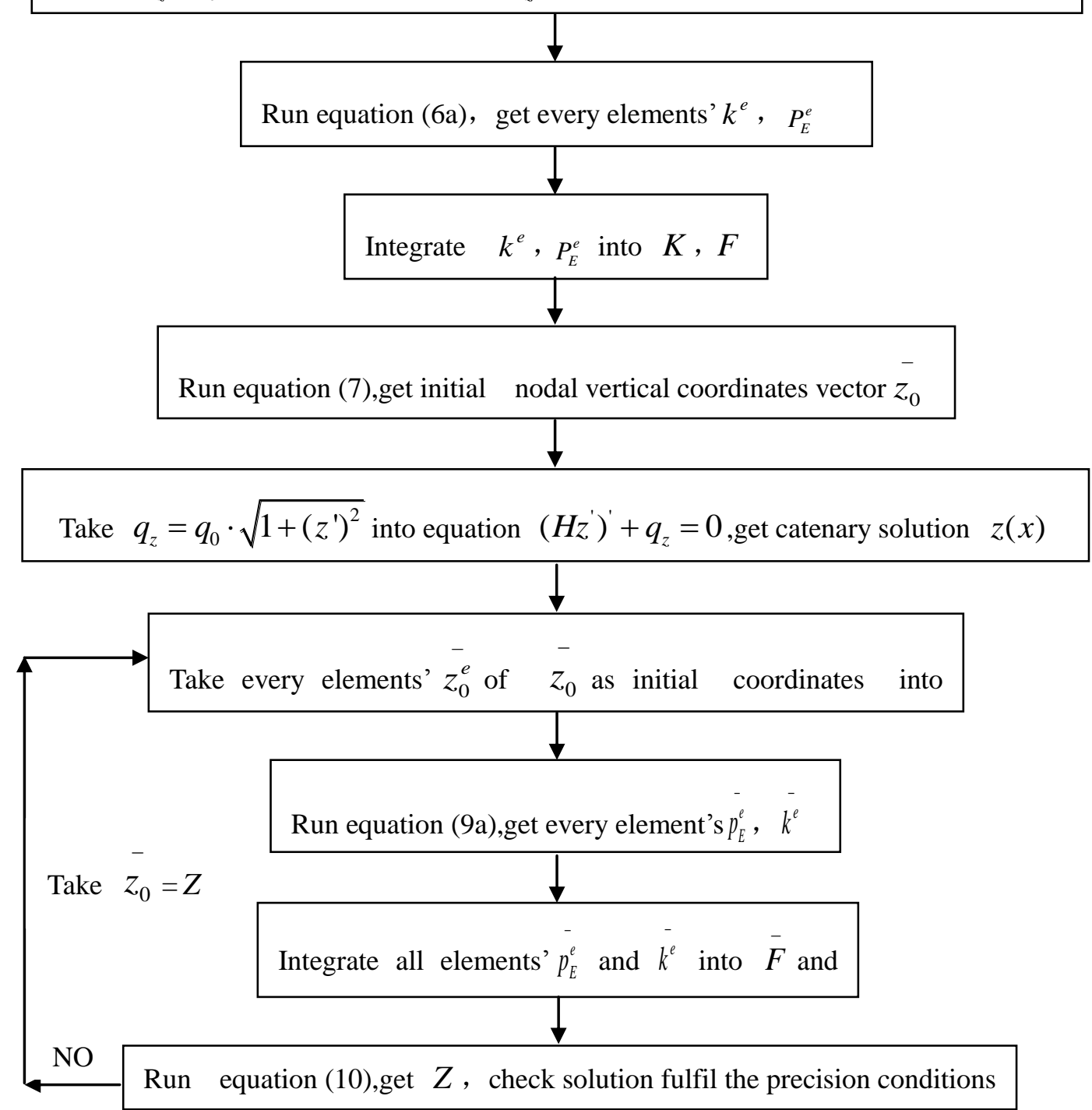




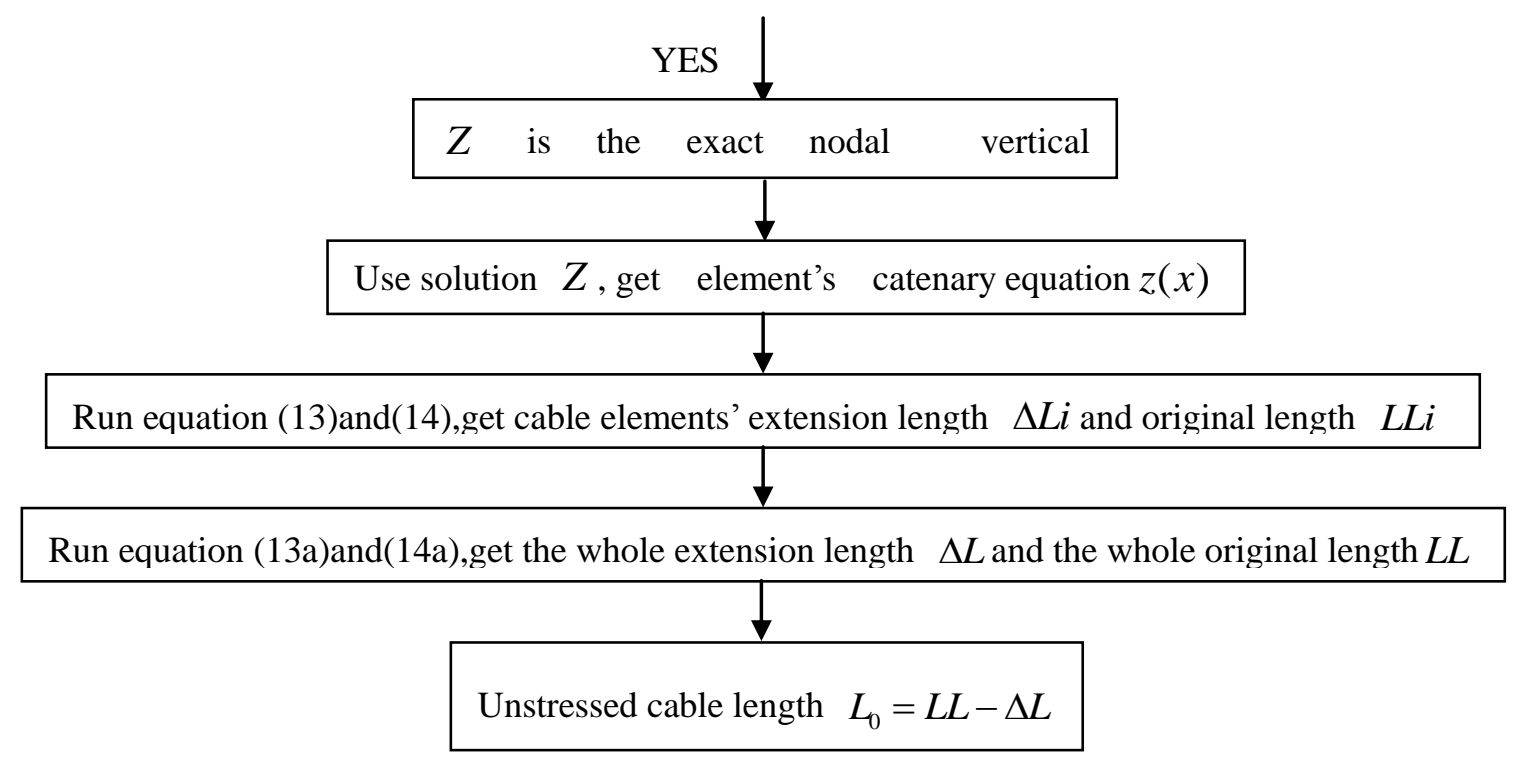

Fig.5 Flowchart of the algorithm for form-finding and unstressed length

\section{FINITE ELEMENT ANALYSIS OF ENGINEERING EXAMPLE}

In the paper, we use two kinds of large finite element software to calculating. In the procedure, the centre-span suspension cable is taken as analysis object, and the calculating structure parameters are measured value, and take the temperature influence into account.

At the empty cable state, the measured coordinates of the top points of JISHOU tower and CHADONG tower are (13978.3, 699.806) , (15764.67,709.169), which will be the start point and finish point of the analysis object. Only take the $1 / 8,1 / 4,3 / 8,1 / 2,5 / 8,3 / 4$ place points as keypoints of the cable, and take the horizontal tension for $\mathrm{H}=5648.7$ ton. The calculated coordinates of all keypoints and unstressed cable length of finite element analysis as shown in table 1.

Tab.1. Form-finding results of finite element software/ $(\mathrm{m})$

\begin{tabular}{ccccc}
\hline \multirow{2}{*}{ Bridge-span } & \multirow{2}{*}{$\mathrm{X}$} & \multicolumn{2}{c}{$\mathrm{Z}$} & \multirow{2}{*}{ Error(\%) } \\
\cline { 3 - 4 } & 13987.3 & 699.806 & 699.806 & $0.00 \%$ \\
$1 / 8$ & 14126.43 & 652.893 & 653.167 & $-0.04 \%$ \\
$1 / 4$ & 14256.93 & 620.856 & 621.041 & $-0.03 \%$ \\
$3 / 8$ & 14430.93 & 595.758 & 595.706 & $0.01 \%$ \\
$1 / 2$ & 14575.93 & 590.014 & 590.866 & $0.01 \%$ \\
$5 / 8$ & 14706.43 & 596.584 & 596.486 & $0.02 \%$ \\
$3 / 4$ & 14873.18 & 621.246 & 621.320 & $-0.01 \%$ \\
$7 / 8$ & 15018.18 & 657.740 & 657.840 & $-0.02 \%$ \\
1 & 15164.67 & 709.169 & 709.169 & $0.00 \%$ \\
\hline
\end{tabular}

As shown in table 1,the calculation results can show us that the max 
vertical coordinates error at the same horizontal coordinate is $0.04 \%$, it can prove results of the two kinds of finite element software are similar; and the max unstressed cable length error between self-made program and finite element software shown in table 2 is $0.006 \%$, it prove the results are exact.

Tab.2. Results of unstressed cable length/ ( $\mathrm{m})$

\begin{tabular}{ccccc}
\hline $\begin{array}{c}\text { Calculation } \\
\text { software }\end{array}$ & $\begin{array}{c}\text { Oringinal } \\
\text { length }\end{array}$ & $\begin{array}{c}\text { Extension } \\
\text { length }\end{array}$ & Unstressed length & $\begin{array}{c}\text { Error with } \\
\text { program }\end{array}$ \\
\hline Midas civil & 1206.579 & 0.759 & 1205.82 & $0.006 \%$ \\
Ansys & 1206.553 & 0.743 & 1205.81 & $0.003 \%$ \\
Procedure & 1206.511 & 0.707 & 1205.804 & $0.000 \%$ \\
\hline
\end{tabular}

\section{COMPARISON BETWEEN THEORETICAL CALCULATION AND MEASURED VALUE}

According to the calculation theory for form-finding, make use of self-made program to calculate the coordinates of keypoints, then compare the results with the results of finite element software and measured value in table 3 and figure 6 , the value in table shows that the max error of self-made program and measured value is $0.012 \%$, it proves the calculation theory exact, the results can fulfill the engineering accuracy.

Tab.3 Form-finding results of Self-made program and measured value/ (m)

\begin{tabular}{ccccc}
\hline & & \multicolumn{3}{c}{$\mathrm{Z}$} \\
\cline { 3 - 4 } Bridge-span & $\mathrm{X}$ & Theoretical calculation & Measured value & Error \\
\hline 0 & 13987.3 & 699.806 & 699.806 & $0.000 \%$ \\
$1 / 8$ & 14126.43 & 652.894 & 652.839 & $-0.008 \%$ \\
$1 / 4$ & 14256.93 & 620.858 & 620.896 & $0.006 \%$ \\
$3 / 8$ & 14430.93 & 595.761 & 595.711 & $-0.008 \%$ \\
$1 / 2$ & 14575.93 & 590.018 & 590.091 & $0.012 \%$ \\
$5 / 8$ & 14706.43 & 596.587 & 596.588 & $0.000 \%$ \\
$3 / 4$ & 14873.18 & 621.248 & 621.257 & $0.001 \%$ \\
$7 / 8$ & 15018.18 & 657.741 & 657.730 & $-0.002 \%$ \\
1 & 15164.67 & 709.169 & 709.169 & $0.000 \%$ \\
\hline
\end{tabular}




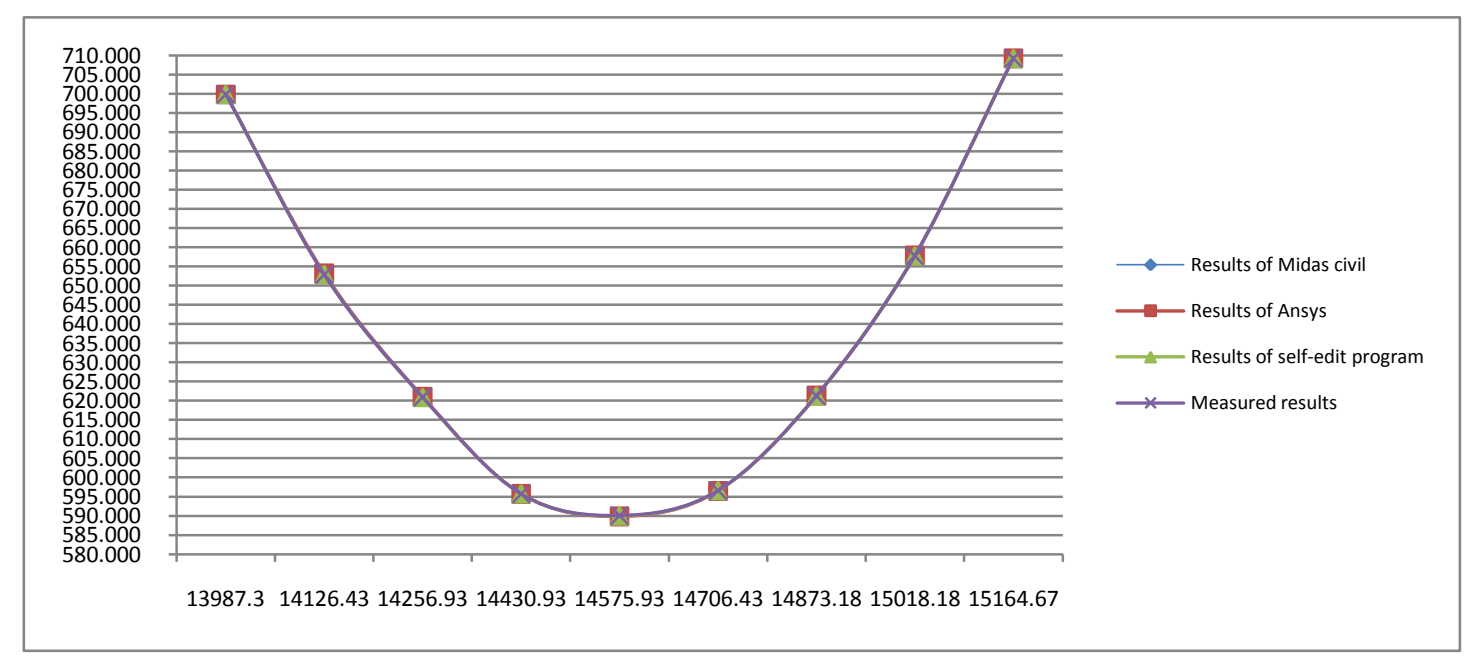

Fig.6 The results curve of finite softwares and self-edit program and measured results

\section{CONCLUDING REMARKS}

1. Compared to the Nonlinear Finite Element method, the method of precise form finding for cable unit can reduce divided unit density and number of elements in matrix calculation so as to improve the operation speed.

2. With the vertical load distribution changing from along the string length to the arc length, cable units converge into accurate catenary by the nonlinear iteration with the initial parabolic value which has been near exact solution. Therefore, the method greatly accelerates the convergence speed.

3. The calculation method is put forward for cable-length in non-stress on the premise that the precise coordinates of suspension cable have been achieved according to theory of precise form-finding for cable element.

4. By taking Aizhai Suspension Bridge as an engineering example, the paper has analyzed the measurements and the results of finite element software, and verifies the accuracy of calculation theory and the self-made calculation program.

\section{Acknowledgements}

This paper cost many people's time and energy. My deepest gratitude goes first and foremost to my tutor, Professor Wang Ronghui, for his constant encouragement and guidance. He has helped me a lot through all the stages of the writing of this paper. Without his constant instruction, this paper can't be managed to reach this present form.

My sincere thanks goes to Wei Yuancheng and Huang Xiaofeng, they also helps me a lot by providing me many useful reference books.

I also owe my thanks to my dear friends and fellow classmates, who have done me a favor in helping me work out my problems during the difficult course of 
the paper.

I would like to deeply thank the all various people who, during the several months in which this endeavor lasted, provided me with useful and helpful assistance. Without their care and consideration, this essay would likely not have finished.

\section{REFERENCES}

[1] SHEN Shi-zhao.XU Chong-bao. Suspension Cable Structure Design[M],BEIJING:China Architecture and Building Press,1997

[2] XIANG Yang,SHEN Shi-zhao.Initial Form-finding Analysis of Cable Structures[J]. Journal of Harbin University of Civil Engineering and Architecture, 1997,30(3):29-33.

[3] YAN Jing-tong,GAO ri.Comparison And Analysis Between Two Form-finding Methods For Cable Net Structures[J].Steel Structure 2002,17(1):4-6.

[4] SCHEK H K.The force densities method for form-finding and computation of general nets[J].Computer Methods in Applied Mechanics Engineering,1974.3(1):115-134.

[5] BARNES M R.Dynamic relaxation analysis of tension networks[A].Proceedings of the International Conference on Tension Structure[C].London,April,1974.

[6] Zhou meng-bo. Suspension bridge manual [M], Beijing:China Communications Press, 2003.8.

[7] YUAN Si, CHENG Da-ye, YE Kang-sheng.. Exact Element Method for Form-finding Analysis of Cable Structures [J].Journal of Building Structures 2005,26(2):46-51.

[8] Wang Xin-ming. ANSYS Engineering structure numerical analysis[M], Beijing:China Communications Press, 2007.10. 